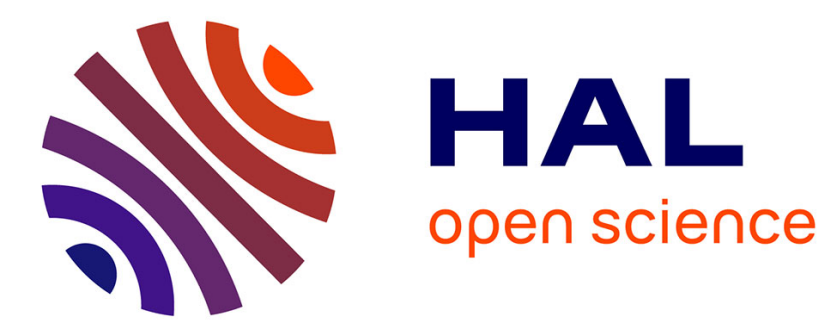

\title{
Arabic Handwritten Words Off-line Recognition based on HMMs and DBNs
}

\author{
Akram Khémiri, Afef Kacem, Abdel Belaïd, Mourad Elloumi
}

\section{To cite this version:}

Akram Khémiri, Afef Kacem, Abdel Belaïd, Mourad Elloumi. Arabic Handwritten Words Off-line Recognition based on HMMs and DBNs. ICDAR 2015 - 13th International Conference on Document Analysis and Recognition, Aug 2015, Nancy, France. pp.51 - 55, 10.1109/ICDAR.2015.7333724. hal-01254724

\section{HAL Id: hal-01254724 https://hal.inria.fr/hal-01254724}

Submitted on 25 Jan 2016

HAL is a multi-disciplinary open access archive for the deposit and dissemination of scientific research documents, whether they are published or not. The documents may come from teaching and research institutions in France or abroad, or from public or private research centers.
L'archive ouverte pluridisciplinaire HAL, est destinée au dépôt et à la diffusion de documents scientifiques de niveau recherche, publiés ou non, émanant des établissements d'enseignement et de recherche français ou étrangers, des laboratoires publics ou privés. 


\title{
Arabic Handwritten Words Off-line Recognition based on HMMs and DBNs
}

\author{
Akram Khémiri*, Afef Kacem Echi*, Abdel Belaïd+ and Mourad Elloumi* \\ *University of Tunis, LaTICE, Tunis, Tunisia \\ +University of Lorraine, LORIA, Nancy, France \\ \{akramkhemiri@gmail.com, afef.kacem@esstt.rnu.tn, abdel.belaid@loria.fr, mourad.elloumi@gmail.com\}
}

\begin{abstract}
In this work, we investigate the combination of PGM (Propabilistic Graphical Models) classifiers, either independent or coupled, for the recognition of Arabic handwritten words. The independent classifiers are vertical and horizontal HMMs (Hidden Markov Models) whose observable outputs are features extracted from the image columns and the image rows respectively. The coupled classifiers associate the vertical and horizontal observation streams into a single DBN (Dynamic Bayesian Network). A novel method to extract word baseline and a simple and easily extractable features to construct feature vectors for words in the vocabulary are proposed. Some of these features are statistical, based on pixel distributions and local pixel configurations. Others are structural, based on the presence of ascenders, descenders, loops and diacritic points. Experiments on handwritten Arabic words from IFN/ENIT strongly support the feasibility of the proposed approach. The recognition rates achieve $90.42 \%$ with vertical and horizontal HMM, 85.03\% and $85.21 \%$ with respectively a first and a second DBN which outperform results of some works based on PGMs.
\end{abstract}

\section{INTRODUCTION}

Because of its high variability and complexity, the Arabic handwriting recognition is still a challenging task for a classifier. As PGM (Probabilistic Graphical Models) classifiers mainly HMMs (Hidden Markov Models) and BNs (Bayesian Networks) are being exercised for writing recognition, showing promising results to handle with uncertainly of human writing, we investigate in this work their use for off-line recognition of Arabic handwritten words. As defined by Srihari and al. [5], PGMs are diagrammatic representations of probability distribution. HMM-based algorithms were designed to handle letters, words, stroke or pseudo-characters using onedimensional, two-dimensional or planar HMMs. Results were very encouraging in the handwritten case and appear to handle the cursiveness well as reported in [6-9]. Some works focused on the use of HMMs for the recognition of isolated forms of Arabic letters or digits only. HMM success can be attributed to the probabilistic nature of HMM models, which can perform a robust modeling of the handwriting.

HMM-based systems received most of the attention, but other PGMs like BNs were also used and proved to have satisfying results. BNs represent a set of random variables and their conditional dependencies via a directed acyclic graph [10], [11]. BNs allow representing probability models in an efficient and intuitive way. A Dynamic Bayesian Network (DBN) is a $\mathrm{BN}$ which relates variables to each other over adjacent time steps. The temporal extension of BN towards DBN have been recently applied to a range of different domains [12], [13]. For that, the observed information used as an input for the DBN is made of pre-extracted features. It is possible to use lowlevel data such as image pixels, by the application of DBNs to character recognition as done by Likforman-Sulem and al. [14]. In Mahjoub and al. [15], multiple models of BNs are applied for off-line recognition of Arabic handwritten tunisian city names. Note that a HMM can be considered the simplest DBN where there is only one observation stream and one state sequence. The main difference between them is that in a DBN the hidden states are represented by a set of random variables whereas in a HMM, the state space consists of a single random variable.

We have built, in a previous work [3], independent and coupled models using DBNs. The independent models are HMM-based architectures which observe either the sequence of feature columns (the vertical-HMM) or the sequence of feature rows (horizontal-HMM). The coupled models combine these two HMM architectures into single DBN. We achieved promising results. But the objective of this work is to investigate further DBN architectures that should enhance the recognition rates. This is done by linking, in different ways, the horizontal and vertical HMMs, each including an observation stream associated with state variables. In the proposed coupled models, the two streams, vertical and horizontal, are jointly observed and reflect the spatial correlations between these observations. The paper is organized as follows. In section II, we present the literature review. In section III, we describe our proposed system based on a new method of word baseline estimation, features extraction and different architectures of PGMs (Vertical-Horizontal HMM and DBNs) and show how our work makes it suitable for handwritten Arabic word recognition. In section IV, we display and discuss some experimental results. Conclusions and prospects are drawn in section $\mathrm{V}$.

\section{LITERATURE REVIEW}

Below is a recapitulative table which summarizes some existing works for off-line writing recognition based on PGMs.

Table I: Some related works based on PGMs.

\begin{tabular}{|l|l|l|}
\hline \multicolumn{1}{|c|}{ Works } & Method & $\begin{array}{l}\text { Recognition } \\
\text { Rate (\%) }\end{array}$ \\
\hline $\begin{array}{l}\text { Mahjoub and al. [15] tested on } \\
\text { Arabic handwritten words from }\end{array}$ & Naïve-BN & 73 \\
TAN & 80 \\
TAN,ENIT databse with Naïve-BN, & FAN & 82.56 \\
\hline $\begin{array}{l}\text { AlKhateeb and DBN models. } \\
\text { Arabic handwritten words from }\end{array}$ & DBN & 83.7 \\
$\begin{array}{l}\text { IFN/ENIT database with ARCPL } \\
\text { model. }\end{array}$ & & \\
\hline
\end{tabular}




\begin{tabular}{|l|l|l|}
\hline $\begin{array}{l}\text { Masmoud and al. [17] tested on } \\
\text { Arabic handwritten words from } \\
\text { IFN/ENIT database with Planar }\end{array}$ & PHMM & 88.7 \\
HMM. & & \\
\hline $\begin{array}{l}\text { AlKhateeb and al. [18] teste on Ara- } \\
\text { bic handwritten digits from ADBase } \\
\text { database with ARCPL model. }\end{array}$ & ARCPL model & 95.26 \\
\hline $\begin{array}{l}\text { Likforman-Sulem and al. [14] tested } \\
\text { on Latin Artificially degraded hand- }\end{array}$ & AR-Vertical & \\
written digits from the MNIST & AR-Horizontal & 93.2 \\
database with AR, STCPL, GNL- & GNLCPL & 92.7 \\
CPL, ARCPL models. & ARCPL & 93.4 \\
\hline $\begin{array}{l}\text { Likforman-Sulem and al. [14] tested } \\
\text { on Real Latin degraded old printed }\end{array}$ & AR-Vertical & 94.9 \\
characters from British Library's col- & STCPL & 94.5 \\
lection of digitized Renaissance festi- & GNLCPL & 91.2 \\
val book wih AR, STCPL, GNLCPL & ARCPL & 95.5 \\
and ARCPL models. & & 96 \\
\hline Pauplin and al. [19] tesed on Latin & Model $_{1}$ & 67.6 \\
handwritten digits from the MNIST & Model $_{2}$ & 69.9 \\
database with 4 models of DBN. & Model $_{3}$ & 74.8 \\
\multicolumn{2}{|l}{ Model $_{4}$} & 71.2 \\
\hline
\end{tabular}

We compared, as it will be shown, our system to similar systems such as those of Mahjoub and al. [15], AlKhateeb and al. [16] and Masmoud and al. [17] which exactly handls with the same problem. AlKhateeb and al [16] used a data fusion scheme which couples two data streams, image columns and image rows into a single DBN classifier. In Mahjoub and al. [15], the word image is divided into three elementary blocks reflecting its local description. For each block (composed of a character or a part of the word), a descriptors vector is computed which includes Zernike and $\mathrm{Hu}$ moments. As these descriptors provide signatures of continuous values and $\mathrm{BN}$ requires discrete variables, a discretization method, based on $\mathrm{K}$-means, is used to transform the variables with continuous values into variables with discrete value. Finally, four variants of BNs were applied (Naïve Bayes, Tree Augmented Naïve Bayes (TAN), Forest Augmented Naïve Bayes (FAN) and DBN) to classify the whole word image. In Masmoud and al. [17], a planar HMM (PHMM) is considered. A PHMM is a HMM whose emission probabilities are also modeled by HMMs. It has a vertical principal model composed of seven super-states: beginning, end and five intermediate superstates associated to the different logical bands (median zone, upper/lower extensions and diacritics zones).

\section{PROPOSED SYSTEM}

The proposed system consists of three main steps: 1) Baseline estimation, 2) Features extraction and 3) Word classification.

\section{A. Baseline Estimation}

Arabic handwritten words are not usually written with a single baseline because of its letter extensions. Thus, position of ascenders and descenders varies according to the writing style. For that reason the system tries not to extract a single baseline for the entire word, but a sequence of sub-baselines. It starts extracting by parts of the arabic words (PAWs) and filtering diacritic signs (see Fig. 1).

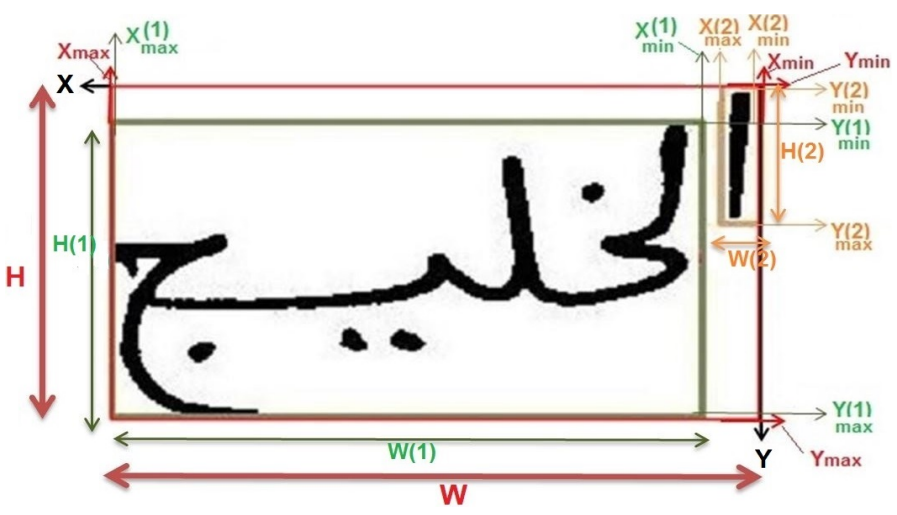

Figure 1. Word and its PAWs spatial coordinates.

For each word composed of $n$ PAWs, their average width, $W i d t h_{A v g}$ is $\frac{\sum_{i=1}^{n} W(i)}{n}$, where $W(i)=X_{\max }(i)-X_{\min }(i)$.

The baseline of each PAW can be estimated as follows:
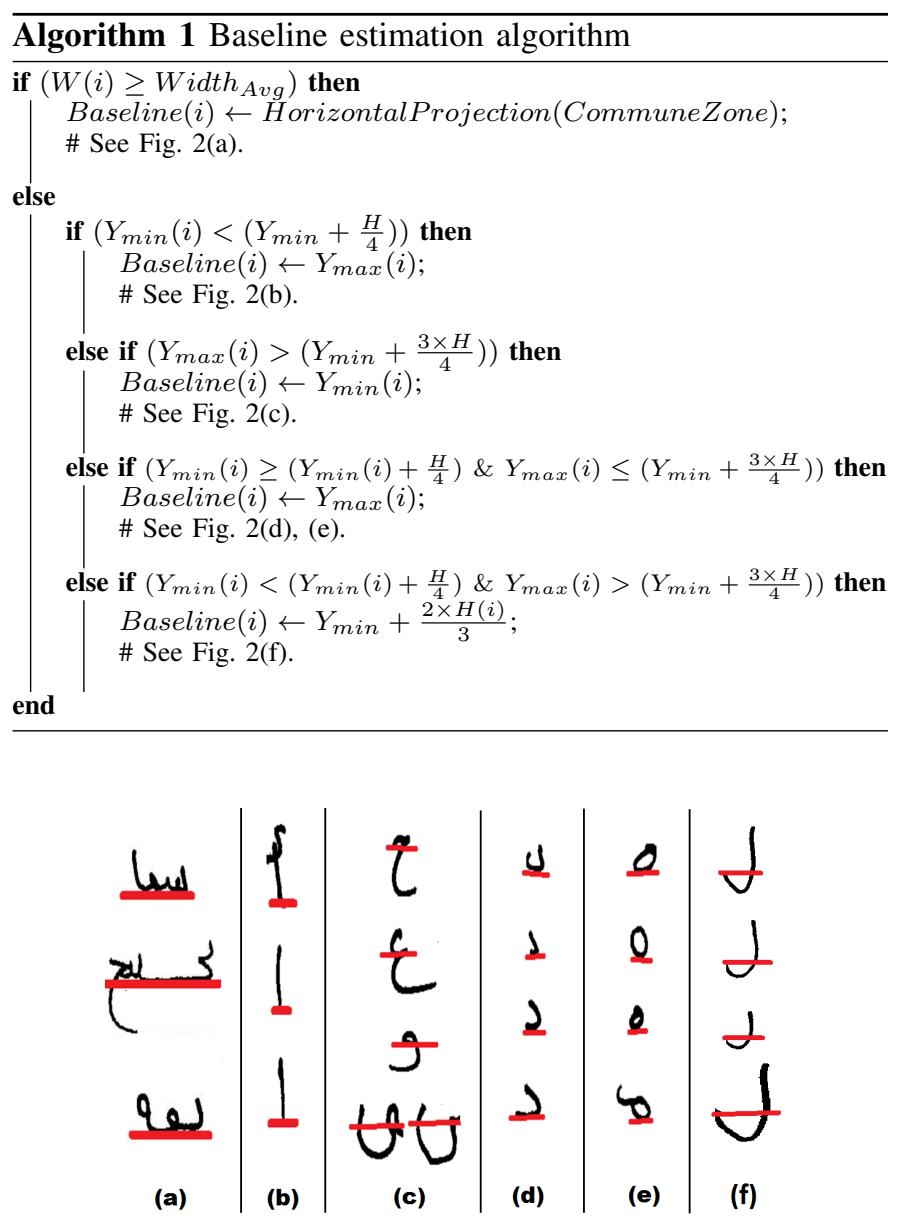

Figure 2. Examples of PAW baseline estimation.

The entire word baseline is formed by juxtaposition of its PAW baselines as shown in Fig. 3 (first column). We compared between this method and the classical horizontal projection in Fig. 3. As it can be seen, the extracted baselines, as we done, fit better to word support lines than those obtained by horizontal projection. 

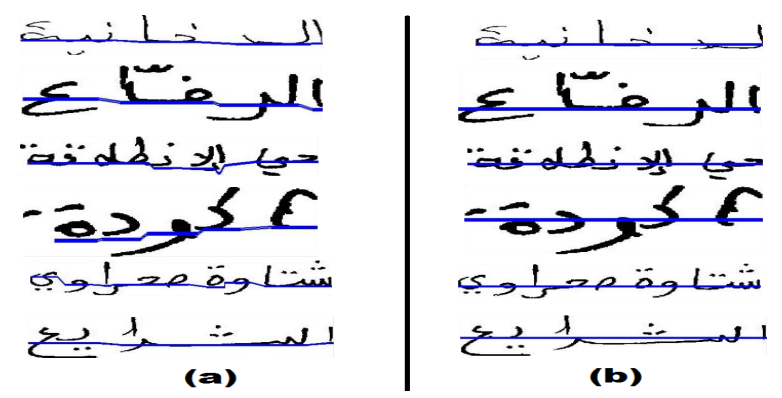

Figure 3. (a) Extracted baseline, (b) Baseline extracted by horizontal projection.

\section{B. Features Extraction}

Once word baseline estimated, the effective word central band can be determined. As Arabic letters without extensions (central letters as تب , ف, etc.), in central band, protrude more above than below the baseline (see Fig. 4), the upper respectively the lower band will be fixed to Baseline-HeightCentralAvg and Baseline +10 pixels, where the HeightCentralAvg is the average height of $m$ central letters height found in words of the database.

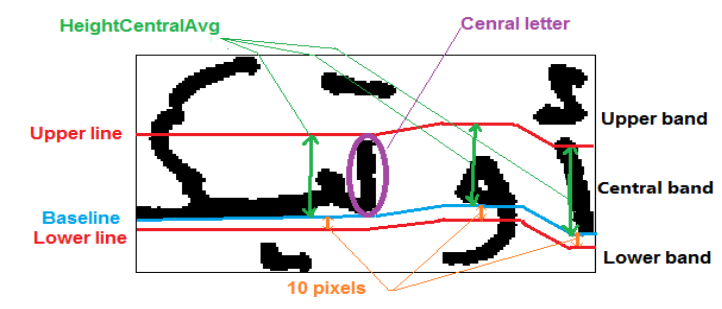

Figure 4. Upper, central and lower band extraction based on baseline.

We extracted some structural features such as diacritic points, ascenders, descenders and loops, using upper, central and lower bands of the word. More precisely, we extracted 30 structural features: 10 features per column: Stem-Alif, StemKef, 1 Diacritic point to top, 2 Diacritic points to top, 1 Diacritic point down, 2 Diacritic points down, loop, Leg-Raa, Leg-Noun and Leg-Haa. For more accurate representation of the word, we locally observed word parts. For that, we divided the word image into 3 rows: $R_{1}, R_{2}$ and $R_{3}$ and 3 columns: $\mathrm{C}_{1}, \mathrm{C}_{2}$ and $\mathrm{C}_{3}$. For each row, from right to left, we computed the number of pixel transitions (white to black or black to white) along a horizontal axis which divides the word image rows in the middle, considering their position in the word: in the beginning $\left(\mathrm{C}_{1}\right.$ : the rightist quarter), in the middle $\left(\mathrm{C}_{2}\right.$ : the middle half) or at the end of the word $\left(\mathrm{C}_{3}\right.$ : the leftist quarter). Note that $C_{2}$ is taken as the sum of $C_{1}$ and $C_{3}$ to consider the elongation aspect, often seen in Arabic script. We noted that the number of pixel transitions can vary from 0 to 5 transitions (6 possible values) per row and column. So 54 values (18 per row). For the columns of a word, we also considered the number of PAWs according to their position in the word (at the beginning $\mathrm{C}_{1}$, in the middle $\mathrm{C}_{2}$ or at the end $\mathrm{C}_{3}$ ). This number varies from 0 to 4 or more. So 15 values ( 5 per column). For more details, see our previous works in Kacem and al. [1-4].

In Fig. 4, we give an example of features extracted from the word 'الحتاج' (Al Haj): For the columns we have: The structural features are: Stem Alif in the beginning, Sem Kaf, Stem Alif and 1 Diacritic Point at the bottom in the middle and a Loop and Leg Haa at the end (see Fig. 5(a)). For the PAWs features we have: 1 PAW in the beginning, 2 PAWs in the middle and 1 PAW at the end (see Fig. 5(b). As shown in Fig. 5(c), there are 2 pixel transitions in $\left(R_{1}, C_{1}\right),\left(R_{1}, C_{2}\right),\left(R_{2}, C_{1}\right),\left(R_{2}, C_{3}\right)$ and $\left(R_{3}, C_{3}\right)$ blocks. There are 6 pixel transitions in $\left(R_{2}, C_{2}\right)$ block and no transitions in the remaining blocks.

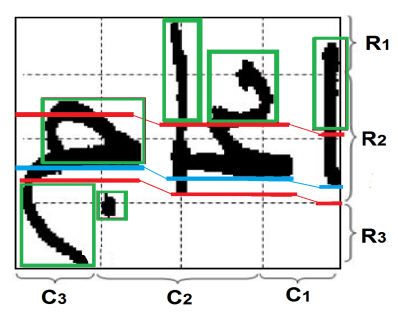

(a)

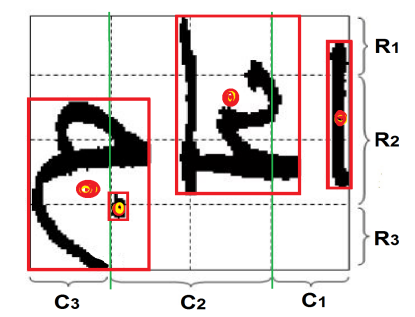

(b)

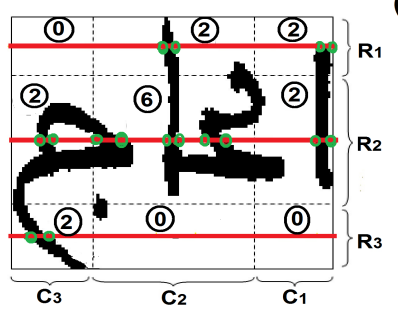

(c)
Figure 5. (a) Structural features. (b) PAWs features. (c) Number of pixel transitions.

\section{Word Classification}

We introduce in this section the independent HMM-based architectures and their combination into single coupled DBNs.

1) Vertical-Horizontal HMM: Here, we conceived an independent two-dimensional HMM which considers features extracted from both columns and rows (see Fig. 6(a)).

- $C_{1}$ is defined by 15 features:10 structural features at the beginning of the word and 5 PAW features $(0,1,2,3$ or $4+$ PAWs) which indicates how many PAWs there are in the beginning of the word. A PAW exists in the beginning if its gravity center belongs to the range of $C_{1}$.

- $C_{2}$ is defined by 15 features, just like $C_{1}$ but only considering the middle of the word.

- $C_{3}$ is defined by 15 features, just like $C_{1}$ but only considering the end of the word..

- $R_{1}$ is defined by 18 features (number of pixel transitions : 0 , $1,2,3,4$ or $5+$ values at the top/beginning, at the top/middle and at the top/end of the word).

- $R_{2}$ is defined by 18 features (just like $R_{1}$ but only considering the number of transitions in $R_{2}$ respectively in the beginning, at the middle and at end of the word).

- $R_{3}$ is defined by 18 features (just like $R_{1}$ but only considering the number of transitions in $R_{3}$ respectively in the beginning, at the middle and at end of the word).

In sum, we used: 30 structural features and 15 PAW features from word columns and 54 features from word rows.

2) Dynamic Bayesian Network: To build a first DBN1, we thought about coupling the V-HMM and H-HMM (vertical 
and horizontal HMMs) by adding direct links between nodes in the graph to represent dependencies between state variables. Adding links requires learning graph structure from data or fixing a DBN structure for all word images. In our case, we set a structure as illustrated in Fig. 6(b), (c): a DBN model based on coupling two HMMs in which we add a causal link (representing the time dependencies) from one time slice to another. The structure is completely known a priori and all variables are observable from the data. Coupled V-HMM and H-HMM are divided into 3 time slices (see Fig. 6(b)). We also conceived a second DBN2 by adding connections between states. The objective is to consider all possible correlations between parts of word (see Fig. 6(c)).

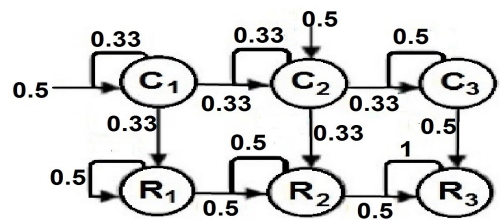

(a)

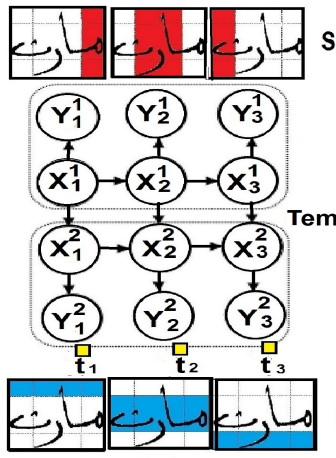

(b)

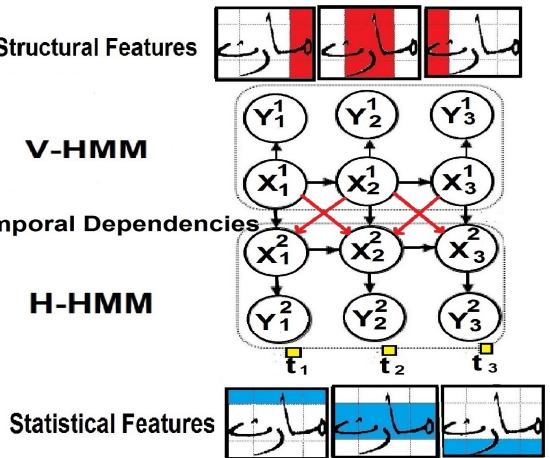

(c)
Figure 6. PGMs models: (a) Vertical-Horizontal HMM. (b) DBN1 architecture based on coupling two hidden Markov chains. (c) DBN2 architecture by adding further links between states.

\section{EXPERIMENTAL RESULTS}

Table II displays obtained results with the proposed models: VH-HMM, DBN1 and DBN2 tested on words extracted from the IFN/ENIT database [20].

Table II: Recognition rate by models

\begin{tabular}{|c|c|c|c|c|}
\hline Word & Samples & DBN1(\%) & DBN2(\%) & $\begin{array}{l}\text { VH- } \\
\operatorname{HMM}(\%)\end{array}$ \\
\hline الرضًاع (Al Radhaa) & 374 & 94.40 & 92.80 & 97.60 \\
\hline الحخليج (Al Khalij) & 345 & 83.49 & 83.49 & 88.69 \\
\hline نقة (Nakka) & 343 & 93.86 & 95.61 & 95.61 \\
\hline شعال (Chaal) & 338 & 92.03 & 94.69 & 95.97 \\
\hline مَارث (Mareth) & 338 & 84.07 & 92.03 & 91.15 \\
\hline شمَاخ (Chamakh) & 322 & 90.65 & 92.52 & 90.65 \\
\hline زنوش (Zannouch) & 319 & 92.45 & 88.68 & 93.40 \\
\hline الُُخَانية (Addokhaniya) & 318 & 89.62 & 87.74 & 92.45 \\
\hline الفُايض (Al Fayedh) & 312 & 85.58 & 89.42 & 87.50 \\
\hline اكودة (Akouda) & 298 & 86.87 & 92.92 & 89.90 \\
\hline سبعة ابَار (Sabaat Abar) & 293 & 93.88 & 91.84 & 94.90 \\
\hline $\begin{array}{l}\text { سيدي ابرَاهيم الزهمَار Sidi Ibrahim } \\
\text { AlZahhar) }\end{array}$ & 290 & 90.72 & 92.78 & 90.72 \\
\hline $\begin{array}{l}\text { المرناقية } 20 \text { مَارس (Al Mornaguiya } \\
\text { 20 Mars) }\end{array}$ & 274 & 93.41 & 93.41 & 94.51 \\
\hline
\end{tabular}

\begin{tabular}{|c|c|c|c|c|}
\hline شتُّاوة صحرَاوي & 245 & 96.34 & 92.68 & 96.34 \\
\hline الفكة (Al Fakka) & 171 & 91.23 & 87.72 & 92.98 \\
\hline اوتيك (Utique) & 138 & 82.61 & 86.96 & 91.30 \\
\hline الفحص (Al Fahs) & 138 & 93.48 & 93.48 & 91.30 \\
\hline الشرَايع (Al Charayaa) & 134 & 82.22 & 86.66 & 95.55 \\
\hline حي الأنطاًاقة (Hay Al Intilaka) & 120 & 80.00 & 75.00 & 90.00 \\
\hline شوَاط (Chawwat) & 109 & 83.33 & 86.11 & 86.11 \\
\hline حي التضَامن (Hay Attadhamon) & 60 & 85.00 & 90.00 & 90.00 \\
\hline ربَانة (Robbena) & 67 & 81.82 & 77.27 & 90.90 \\
\hline رقادة (Rakkada) & 63 & 90.48 & 85.71 & 90.48 \\
\hline النًاضور (Annadhour) & 54 & 66.67 & 61.11 & 88.88 \\
\hline روَاد (Rawwed) & 71 & 70.83 & 79.16 & 87.5 \\
\hline النفيضة (Annfidha) & 22 & 71.43 & 71.43 & 85.71 \\
\hline (Arragoba) الرقوبة & 95 & 60.61 & 60.61 & 69.70 \\
\hline الهيشية (Al Hichriyya) & 14 & 100.0 & 100.0 & 100.0 \\
\hline ) قربص (Korbos) & 91 & 86.67 & 86.67 & 90.00 \\
\hline الشُابة (Achebba) & 71 & 54.17 & 66.66 & 50.00 \\
\hline المحرص (Al Mahres) & 76 & 84 & 88.00 & 80.00 \\
\hline دوَار هيشر (Douar Hicher) & 56 & 63.16 & 73.68 & 78.95 \\
\hline طبَابة (Tabbeba) & 37 & 83.33 & 66.66 & 91.66 \\
\hline السبَالة (Assabela) & 28 & 88.89 & 88.89 & 88.89 \\
\hline حفوز (Haffouz) & 49 & 75 & 68.75 & 87.50 \\
\hline رَأس الجبل (Ras Jebal) & 9 & 100.0 & 100.0 & 100.0 \\
\hline رفراف (Rafraf) & 18 & 83.33 & 66.66 & 100.0 \\
\hline بنزرت (Bizere) & 9 & 100.0 & 100.0 & 100.0 \\
\hline بَاجة (Beja) & 17 & 100.0 & 100.0 & 100.0 \\
\hline نُابل (Nabeul) & 16 & 60.00 & 60.00 & 80.00 \\
\hline غُار الملح (Ghar El Melh) & 28 & 77.78 & 77.78 & 88.88 \\
\hline القطار (Al Ktar) & 4 & 100.0 & 100.0 & 100.0 \\
\hline قبلَاط (Kbollat) & 83 & 82.14 & 85.71 & 92.86 \\
\hline مَاطر (Mateur) & 16 & 100.0 & 100.0 & 100.0 \\
\hline برقو (Bargou) & 19 & 66.67 & 66.67 & 100.0 \\
\hline الحَامة (Al Hamma) & 78 & 80.77 & 76.92 & 76.92 \\
\hline رمَادة (Rmeda) & 15 & 80.00 & 80.00 & 100.0 \\
\hline (Sbih) صبيح & 41 & 78.57 & 85.71 & 85.71 \\
\hline بَاردو (Bardou) & 15 & 100.0 & 100.0 & 80.00 \\
\hline سوسة (Sousse) & 7 & 100.0 & 100.0 & 100.0 \\
\hline Total & 6451 & 85.03 & 85.21 & 90.42 \\
\hline
\end{tabular}

As it can be seen, the highest rate was achieved when using an independent VH-HMM: 90.42\%. In assessing the models on short words (having two PAWs at most such as shown in Fig. 7(a)) and long words (with at least three PAWs as done in Fig. 7(b)) and flat words (with two extensions at most(Fig. 7(c)) vs. extended words (having at least three extensions (Fig. 7(d)), we find that the best recognition rates are from long and/or extended words as shown in Table III. The more the word is long and/or extended, the more it contains PAWs, ascenders and descenders, the better will be represented by its structural features and consequently will be well recognized compared to and/or flat words.

Table III. RECOGNITION RATES BY TYPES OF WORDS.

\begin{tabular}{|l|l|l|l|}
\hline Types of words & DBN1(\%) & DBN2(\%) & VH-HMM(\%) \\
\hline Short words & 84.38 & 84.49 & 88.40 \\
\hline Long words & 85.56 & 85.90 & 90.95 \\
\hline Flat words & 84.85 & 84.48 & 89.21 \\
\hline Extended words & 85.28 & 85.51 & 90.50 \\
\hline
\end{tabular}




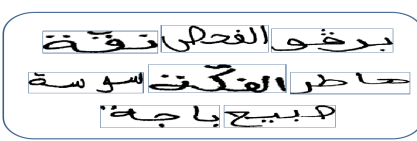

(a)

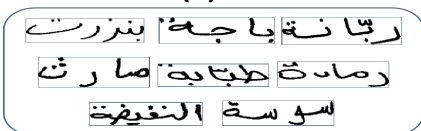

(c)

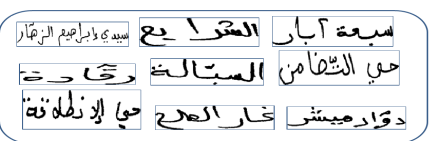

(b)

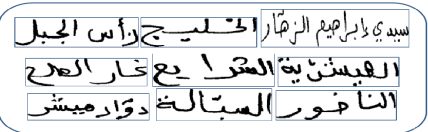

(D)
Figure 7. (a) Short words. (b) Long words. (c) Flat words. (d) Extended words.

Table IV shows results obtained by some related works. It should be noted that since the methods involved use different protocols and different subsets of the IFN/ENIT dataset, it is not possible to make a fair comparison. Actually, we only focused on some specific works which are closely related to our objective: PGM-based system for Arabic handwritten word recognition. So, we just considered works based on DBN or planar HMM which is a 2D-HMM and not works based on 1D-HMMs.

Table IV. OVERVIEW OF SOME RELATED WORK RESULTS.

\begin{tabular}{|l|l|l|l|}
\hline Systems & Data & Method & $\begin{array}{c}\text { Recognition } \\
\text { Rate (\%) }\end{array}$ \\
\hline AlKhateeb and al. [16] & IFN/ENIT & HMM & 82 \\
& & DBN & 66.56 \\
\hline Masmoudi and al. [17] & 25-words & Planar HMM & 88.7 \\
& 2347-samples & & \\
\hline Mahjoub and al. [15] & 18-words & FAN & 82.56 \\
& 3600-samples & TAN & 80 \\
& & Naïve-BN & 73 \\
& & DBN & 83.7 \\
\hline Our system & 50-words & DBN1 & 85.03 \\
& 6451-samples & DBN2 & 85.21 \\
& & VH-HMM & 90.42 \\
\hline
\end{tabular}

From experiments, conducted using a subset from IFN/ENIT benchmark database, the recognition rates achieved by the proposed VH-HMM and DBN models, in comparison to some related works, are among the best for the same task. Overall, we achieved very promising results.

\section{CONClusion}

The goal of this work is to conceive and carry out an automatic off-line recognition system of Arabic handwritten words based on PGMs. We build a variety of models, including a Vertical-Horizontal HMM. We also coupled data streams into DBN classifiers. This coupling is performed through a DBN architecture which combines two basic HMM: the HHMM whose outputs are structural features extracted from word image columns and V-HMM whose outputs are statistical features extracted from word image rows. Both structural features (ascenders, descenders, diacritic points and loops) and statistical features at pixel level in particular pixel density distributions and local pixel configurations are extracted scanning the word binary images from right to left and top to bottom. Additionally, we introduced a novel baseline word estimation to increase the recognition accuracy of deformed or inclined Arabic words. In the proposed DBNs, the interactions are performed through states leading to efficient model in terms of model complexity. In our framework, all word classes share the same DBN architecture. We show models interest in off-line Arabic handwritten word recognition. In order to validate the proposed models, extensive experiments were conducted using the IFN/ENIT database. Experimental results and quantitative evaluations showed that VH-HMM outperforms DBNs in terms of higher recognition rate and lower complexity. In fact, the highest rate was achieved when using an independent VH-HMM: $90.42 \%$. We plan to look for the best representation of the Arabic word image respecting its morphology and to test with other architectures which may provide higher performance.

\section{REFERENCES}

[1] A. Kacem, N. Aouïti, A. Belaïd, "Structural Features Extraction for Handwritten Arabic Personal Names Recognition", Proc. of ICFHR, 268 - 273, 18-20 September, Italy, 2012.

[2] A. Kacem, A. Khémiri, N. Aouïti, N. Aouadi, "Système, à base de MMC, pour la reconnaissance de noms propres manuscrits Arabes", Proc. of CIDE, 16-18 October, Tunisia, 2012.

[3] A. Khémiri, A. Kacem, A. Belaid, "Towards Arabic Handwritten Word Recognition via Probabilistic Graphical Models", Proc. of ICFHR, 1-4 September, Island crete, 2014.

[4] A. Kacem, A. Khémiri, A. Belaïd, "A PGM-based System for Arabic Handwritten Word Recognition", ELCVIA,13(3):41-62, 2014.

[5] S. Srihari, "Machine Learning and Probabilistic Graphical Models Course", www.cedar.buffalo.edu/ srihari/CSE574/, 2010.

[6] F. Biadsy, R. Saabni, J. El-Sana, "Segmentation-Free Online Arabic Handwriting Recognition”, IJPRAI, 1009-1033, 2011.

[7] M. El Yacoubi, R. Gilloux, C. Sabourin, Y. Suen, "An HMM-based approach for off-line unconstrained handwritten word modelling and recognition", IEEE Transactions on PAMI, 21(8):752-760, 1999.

[8] V. Margner, H. Abed, M. Pechwitz, "Offline Handwritten Arabic Word Recognition Using HMM: a Character Based Approach without Explicit Segmentation", Proc. of CIFED, 18-21, Fribourg, Swiss, 2006.

[9] A. Benouareth, A. Ennaji, M. Sellami, "Arabic Handwritten Word Recognition Using HMMs with Explicit State Duration", EURASIP, 2008.

[10] D. L. Kelly, C. L. Smith, "Bayesian inference in probabilistic risk assessment: The current state of the art", Reliability Engineering and System Safety, 94(2):628-643, 2009.

[11] S. Russell, P. Norvig, "Artificial Intelligence, A Modern Approach", 2nd edn. Prentice Hall, Englewood Cliffs, 2003.

[12] K. P. Murphy, "Dynamic Bayesian Networks, Representation, Inference and Learning", PhD dissertation, UC Berkeley, Computer Science Division, July 2002 .

[13] V. Mihajlovic, M. Petkovic, "Dynamic Bayesian Networks, A State of the Art", CTIT technical reports series, TR-CTIT-34, 2001.

[14] L. Likforman-Sulem, M. Sigelle, "Recognition of degraded characters using dynamic Bayesian networks", Pattern Recognition, 41(10):30923103,2008

[15] M. A. Mahjoub, N. Ghanmy, K. Jayech, I. Miled, "Multiple models of Bayesian networks applied to offline recognition of Arabic handwritten city names", Computer Vision and Pattern Recognition, 2013.

[16] J. H. AlKhateeb, O. Pauplin, J. Ren, J. Jiang, "Performance of hidden Markov model and dynamic Bayesian network classifiers on handwritten Arabic word recognition", knowledge-based systems, 24(5):680-688, July 2011.

[17] S. Masmoudi Touj, N. Essoukri Ben Amara, H. Amiri, "Arabic Handwritten Words Recognition Based on a Planar Hidden Markov Model", IAJIT, 2(4):318-325, 2005.

[18] J. H. AlKhateeb, "Offline Handwritten Arabic Digit Recognition Using Dynamic Bayesian Network", Proc. of ICCIT, 176-180, 2012.

[19] O. Pauplin, J. Jiang, "A Dynamic Bayesian Network Based Structural Learning towards Automated Handwritten Digit Recognition", Proc. of HAIS the 5th international conference on Hybrid Artificial Intelligence Systems, 120-127,2010.

[20] Website of IFN-ENIT database, http://www.ifnenit.com/, September 2006. 